\title{
Características del microcrédito en la industria manufacturera de la ciudad de Pasto, año 2016
}

\section{Characteristics of microcredit in the manufacturing industry of Pasto city, 2016}

\section{Resumen}

Artículo de investigación.

Fecha de recepción: 25/06/2020

Fecha de devolución: 08/10/2020

Fecha de aceptación: 22/10/2020

Fecha de publicación: 29/10/2020

\section{Marco Antonio Burgos Flórez Universidad de Nariño. \\ Pasto, Nariño (Colombia) marcoantonioburgos@gmail.com}

\section{Gissela Fernanda Guerrero Díaz Universidad de Nariño. Pasto, Nariño (Colombia) fernanda_g54@hotmail.com}

\section{Harleth Fabricio Mier Goyes Universidad de Nariño. Pasto, Nariño (Colombia) fabriciomiergoyes@gmail.com}

\section{Leticia Rodríguez López Universidad de Nariño. Pasto, Nariño (Colombia) leticiar11993@gmail.com}

\begin{abstract}
Para citar este artículo:
Burgos, M.; Guerrero, G., Mier, H. \& Rodríguez, L. (2021) Características del microcrédito en la industria manufacturera de la ciudad de Pasto, año 2016. Económicas CUC, 42(1), 54-77. DOI: https://doi. org/10.17981/econcuc.42.1.2021.Econ.4
\end{abstract}

JEL: G10, M21, O16
Para las microempresas existen grandes dificultades para financiarse dada su poca calidad crediticia, haciendo que se les restrinja el crédito tradicional $y$, a su vez, motivando el uso de fuentes de financiación informales. No obstante, el microcrédito se establece como una alternativa de financiamiento de enorme potencial en el desarrollo económico regional, ya que incentiva la iniciativa empresarial y posibilita consolidar una respuesta empresarial a las necesidades de los sectores menos favorecidos, lo que sin lugar a dudas impacta sobre la pobreza y, por ende, en el desarrollo. El presente artículo, tiene como objetivo determinar las características del microcrédito y el nivel de satisfacción de sus usuarios, en el sector industrial manufacturero de Pasto. Para ello, la investigación tiene un enfoque cuantitativo, desarrollándose un tipo de estudio descriptivo, el cual se basó en una encuesta aplicada a 315 microempresas manufactureras del municipio de Pasto en el año 2016. Los resultados muestran que el $64,76 \%$ de las microempresas manufactureras accedieron al microcrédito, evidenciando la presencia moderada de exclusión y autoexclusión financiera en ese segmento empresarial. Adicionalmente, los usuarios del microcrédito revelaron una baja educación financiera debido a su desconocimiento sobre las características del servicio: tasa, cuota, plazo, etc. Por último, se destaca que, si bien los usuarios de microcrédito, por lo general, afirmaron que el microcrédito fue oportuno, suficiente y de fácil acceso, perciben el servicio como costoso, sin embargo, la gran mayoría estableció estar satisfecho con el servicio y un $67 \%$ estaría dispuesto a continuar haciendo uso del microcrédito.

Palabras clave: Capital; microcrédito; microempresa; riesgo; sector manufacturero

\begin{abstract}
For microenterprises, there are great difficulties to finance themselves given their poor credit quality, causing them to restrict traditional credit and, in turn, encouraging the use of informal sources of financing. However, microcredit is established as a financing alternative with enormous potential in regional economic development, since it encourages entrepreneurship and makes it possible to consolidate a business response to the needs of the least favored sectors, which undoubtedly impacts on poverty and, therefore, in development. The present article, aims to determine the characteristics of the microcredit and the level of satisfaction of its users, in the industrial manufacturing sector of Pasto. Therefore, the research has a quantitative approach, developing a type of descriptive study, which was based on a survey applied to 315 manufacturing microenterprises of the municipality of Pasto in 2016. The results show that $64.76 \%$ of manufacturing microenterprises accessed to the microcredit, evidencing the moderate presence of exclusion and financial self-exclusion in that business segment. Additionally, microcredit users revealed a low financial education due to their lack of knowledge about the characteristics of the service, like interest rate, fee, term, etc. Finally, it should be noted that, although microcredit users generally stated that the microcredit was appropriate, sufficient and easily accessible, perceive the service as expensive, however, the vast majority stated that they were satisfied with the service and $67 \%$ would be willing to continue making use of the microcredit.

Keywords: Capital; microcredit; microenterprise; risk; manufacturing sector
\end{abstract}




\section{INTRODUCCIÓN}

En Colombia, el microcrédito es un préstamo de bajo monto facilitado por entidades del sector financiero tradicional y no tradicional a las microempresas de las diferentes actividades económicas, el cual es destinado a satisfacer necesidades de capital de trabajo, inversión, ampliación y/o mejoramiento de instalaciones, capacitación, pago de deuda, vivienda, educación y consumo. Por lo general, dado el riesgo derivado de las características de los microempresarios, el microcrédito tiene un precio mayor al crédito tradicional, pero es muy bajo con relación al crédito informal. Al comparar los costos reales de las tres modalidades de crédito (informal, tradicional y microcrédito), Ordoñez y Guerra (2014) encuentran que "la tasa de crédito informal es 12.50 veces mayor que la del crédito tradicional y 5.99 veces al microcrédito" (p. 66).

Esta modalidad de crédito, responde a la política económica de inclusión financiera del país, que, en las últimas dos décadas, los noventa y los dos mil, ha tenido un mayor desarrollo, gracias a adecuaciones legales a la operación financiera y a la disponibilidad de recursos para la actividad.

Para el año 2016, son dos los estudios existentes del microcrédito en el sector empresarial de Pasto, sin embargo, no se han enfocado al estudio particular del sector manufacturero, un sector productivo que comprende todas las unidades productivas que se dedican a la transformación de materias primas e insumos en productos nuevos, ya sea que el trabajo se efectúe con máquinas o a mano (Departamento Nacional de Estadísticas-DANE, 2012), y que como lo afirma la Superintendencia de Sociedades (Supersociedades, 2016), en su Desempeño del sector de manufactura en el periodo 2013-2015, es uno de los más importantes del país, tanto por sus grandes aportes en la generación de empleo, así como en el avance de la industrialización.

Lo que sin duda justifica una investigación del microcrédito en tan importante sector, el cual determine las características del microcrédito y las percepciones de los usuarios frente al servicio, en especial, del microcrédito manufacturero, permitiendo ver su importancia, la complejidad en su acceso y las acciones para su mayor cobertura y contribución al ámbito regional.

Para ello, seguido de esta primera sección introductoria, se presenta una segunda sección, que enmarca el ámbito de las características del microcrédito manufacturero, las condiciones particulares de dicha actividad financiera y su importancia en el desarrollo regional. La tercera sección, muestra un panorama general sobre el microcrédito en Colombia y en el municipio Pasto, su desarrollo e importancia en los últimos años, ello con el fin de establecer un entorno de la actividad microfinanciera para las microempresas manufactureras.

Posteriormente, la cuarta sección, detalla los aspectos metodológicos de un estudio descriptivo, soportado en los resultados de una encuesta realizada a una muestra de 315 microempresas del sector industrial manufacturero del municipio de Pasto en el año 2016. La quinta sección, establece los resultados de la investigación, en la cual se analiza el microcrédito en el sector manufacturero en la ciudad de Pasto, con las características de las microempresas usuarias, así como también. las características, satisfacción y dificultades del microcrédito obtenido. Finalmente, la sexta sección, presenta las conclusiones del estudio. 


\section{Constructo Teórico}

\section{Características del microcrédito manufacturero}

Como todo mercado, el mercado financiero está conformado por una oferta y una demanda, en este caso, prestamistas y prestatarios, quienes actúan de acuerdo con sus propias expectativas y aspiraciones y que fluctúan en torno a un precio (tasa de interés). Por ello es que las tasas de interés tienen que ver con el riesgo; un prestamista no puede saber si un determinado cliente es bueno o malo, por lo tanto, ante el riesgo de que incumpla, la respuesta es subir el tipo de interés. Pero esto afecta a los buenos clientes porque las tasas de interés son para todos, quedando el prestamista en la necesidad de hacer racionamiento de créditos, entendida esta como la negación del crédito a algunos de los solicitantes seleccionados por algún mecanismo diferente al precio que puede ser la calidad crediticia del solicitante (Rodríguez \& Venegas, 2012), lo cual excluye a los sectores de más baja escala productiva, es decir se prioriza el crédito corriente sobre el microcrédito.

El racionamiento crediticio, surge en la medida que existen fallas en la información (información asimétrica), que no permiten una coordinación eficiente entre la Institución Financiera y el Cliente. Es así como se establece que "esta incertidumbre es corregida mediante un alza a las tasas de interés, o la restricción a los montos, de manera que pueda cubrir los costos generados por este problema de asimetría en la información” (Rodríguez, 2010, p. 11). Lo anterior determina, que los microcréditos por lo general son costosos y escasos, de ahí que es interesante indagar cuál es el cubrimiento de los microcréditos en el sector microempresarial, en este caso del sector manufacturero formal, lo cual vislumbra que es un crédito con tasas mayores a las del crédito formal y al cual no todos los microempresarios tienen acceso.

En la dinámica microcrediticia cobra especial interés, el aspecto de que estos créditos deben asegurarse en su pago continuo, y son esas condiciones de exigencias las que crean dificultades para su obtención, así como el seguimiento continuo al usuario por parte de la entidad microcrediticia. Por ello, un elemento atractivo en el análisis del microcrédito lo constituye, el conocer si estos microempresarios invirtieron los recursos del crédito en la actividad productiva, así como también preguntarles cómo esas condiciones de otorgamiento del crédito generan dificultades para su acceso.

Una adecuada explicación de la incidencia de la información asimétrica en la concesión de créditos, la plantea Giraldo (2012), en su estudio sobre el microcrédito como solución al racionamiento de crédito, donde afirma que:

En el mercado de crédito existe información asimétrica cuando una de las partes involucradas en un contrato no cuenta con toda la información relevante sobre las características del otro contratante. Teniendo en cuenta estos comportamientos, las entidades bancarias se comportan óptimamente si restringen el crédito, pues no pueden diferenciar entre deudores buenos, de bajo riesgo, y deudores malos, de alto riesgo. Esta diferencia hace especial al mercado de crédito, porque las promesas se pueden incumplir y es difícil evaluar los riesgos de incumplimiento (p. 18). 
Es así como, dada la dificultad de los entes financieros de responder a los problemas presentados por la asimetría de la información, con tasas de interés diferenciadas por prestatarios y más altas por los riesgos; los bancos como principal ente crediticio responden con el racionamiento del crédito y en ello la exclusión microempresarial, fruto de la relación entre tamaño empresarial y acceso al crédito. Dicho tamaño empresarial relaciona los aspectos de organización y conocimiento financiero, capacidad de pago, liquidez y solvencia, que combinados con la restricción al crédito hace que las empresas de mayor tamaño se lleven casi todos los recursos del sector bancario tradicional, de ahí que siendo necesario ampliar el crédito a los demás sectores empresariales, se han creado una serie de instituciones especializadas para llegar a aquellos clientes excluidos del sistema financiero tradicional, las denominadas entidades microfinancieras.

Estas entidades, a pesar de que realizan una importante labor al darle al crédito una mayor cobertura, todavía presentan un gran reto para ampliarlo, dado su tamaño y los costos que asumen dado el riesgo del prestamista. Dicho costo, es minimizado con varias estrategias, dada su especialización y conocimiento del cliente, así como un importante seguimiento al usuario, lo que muestra al microcrédito como una actividad muy particular de un crédito con permanente contacto con el deudor, que como lo afirma Berger (2000), "el microcrédito difiere significativamente de los préstamos comerciales tradicionales en cuanto el tamaño de los créditos es inferior y su plazo de vencimiento más breve, y se basan más en la reputación, que en las garantías económicas" (p. 1).

Ante ello, se ha hecho necesario el uso de herramientas especiales diseñadas para mitigar los riesgos de la operación, las cuales deben ajustarse a las características del negocio de los microempresarios, entre las que pueden mencionarse: la inexistencia de garantías idóneas, bajos niveles o ausencia de activos, falta de información personal y comercial confiable, inadecuado registro de las operaciones de sus negocios y por lo general una gran demanda de mano de obra no calificada (Banco de la República, 2010). Cabe destacar que los microcréditos generan los denominados costos de seguimiento resultado de la actividad que debe realizar el ente financiador a las acciones del deudor; tales costos se trasladan como un costo adicional del crédito vía tasa de interés, lo que sin lugar a dudas perjudica al deudor encareciendo el crédito (Ricardo, Arango y Taboada, 2020; Rodríguez, 2010).

Como se ha planteado antes, la gran dificultad que tienen las microempresas es acceder al crédito por la exigencia de garantías que disminuyan el riesgo de insolvencia, cuya imposibilidad obliga a buscar otras opciones de crédito con el costo que ello acarrea, algunos países desarrollados han luchado contra ese problema dándole créditos a los empresarios respaldados en la fortaleza del proyecto empresarial, sin solicitar ningún tipo de aval (Ricardo et al., 2020; Gutiérrez, 2006).

No cabe duda de que el microcrédito es una herramienta importante en el desarrollo de una sociedad más igualitaria, con menos pobreza, pero su impacto es mayor, en la medida que llegue de manera más directa al microempresario para su proceso productivo, sea bien administrado y, además, puesto en proyectos rentables. Soportar el crecimiento microempresarial con microcrédito posibilitaría elevar las rentas de 
dichos establecimientos, e incluso, mejorar los niveles de vida del emprendedor y su familia.

En ese sentido, el microcrédito productivo está situado en la línea de sostenibilidad financiera. De ahí su carácter de valorar al sistema financiero como elemento importante para masificar el crédito, apoyando al sistema en ese empeño desde el ámbito estatal, logrando disminuir la pobreza con microcréditos productivos y no con créditos asistencialistas. Este enfoque es de apoyo a la microempresa, se busca más la sostenibilidad financiera y se trabaja con personas excluidas del sistema financiero (González, 2011).

Al estudiar de manera particular el microcrédito productivo y en especial el microcrédito en las microempresas del sector manufacturero, este estudio se enmarca dentro de un enfoque financiero, de ahí la necesidad de establecer las empresas legalmente constituidas que hayan sido usuarias de microcréditos, es decir un nicho de mercado financiero productivo identificado. Claro está que este enfoque financiero plantea acciones del microcrédito de forma estratégica para mejorar los niveles de producción, y con ello aportar a mejorar los niveles de desarrollo de la sociedad, donde estas microempresas necesitan créditos que se ajusten a sus características: inexistencia de garantías, ausencia de activos, falta de información empresarial, con limitados estándares tecnológicos e intensivas en mano de obra no calificada y con bajos sueldos (Banco de la República, 2010).

\section{El microcrédito en Colombia y en el municipio de Pasto}

El término microcrédito ha tomado un papel preponderante en las economías locales debido a su importancia en el sector microempresarial. En Colombia, los inicios del microcrédito se remontan desde los años treinta como una iniciativa para apoyar las necesidades financieras de la población vulnerable. Inicialmente, fue el sector público, el principal proveedor de servicios financieros subsidiados, en especial orientado a los pequeños agricultores, dichos servicios financieros se otorgaban a bajas tasas de interés y con bajas garantías de la deuda (Barona, 2004).

Posteriormente, en los años ochenta comenzaron a surgir las entidades microfinancieras especializadas, las cuales prestaban dinero en pequeñas cantidades, enfocando su nicho de mercado principalmente en mujeres microempresarias que no tenían activos para dar en garantía. Estas formas de apalancamiento comenzaron a emerger particularmente entre organizaciones registradas como sin ánimo de lucro o bancos con estructura jurídica especial (Barona, 2004).

Estas organizaciones microfinancieras, tuvieron su inspiración en los preceptos y experiencias del catedrático de Economía Dr. Muhammad Yunus, quien comenzó su lucha contra la pobreza en 1974 durante la hambruna que padeció la población de Bangladesh. Yunus descubrió que cada pequeño préstamo podía producir un cambio sustancial en las posibilidades de alguien sin otros recursos para sobrevivir, así vio la importancia de desarrollar programas dirigidos a ofrecer crédito sin garantías para actividades generadoras de ingresos, encaminados a superar la pobreza (Rodríguez, 2010). 
De ahí que, los microcréditos sean definidos como aquellos préstamos de pequeñas cantidades que se entregan a personas vulnerables en riesgo de exclusión para ayudarles a poner en marcha un proyecto empresarial o laboral, y que no tienen garantías para su desarrollo. Así, los microcréditos son la única vía para muchos emprendedores de materializar dicha idea que le permitirá entrar en la dinámica productiva y laboral (Ricardo et al., 2020; Rodríguez, 2010).

Retomando el caso de Colombia, autores como Ricardo et al. (2020), Salazar, Martínez y Giraldo (2015) y Garavito (2016) coinciden en afirmar que en los últimos años, el país ha registrado notables avances en el acceso de las microempresas a la financiación, siendo un factor importante de ello la promulgación la Ley 590 (2000), la cual propuso brindar un adecuado acceso de las microempresas a las entidades de crédito en especial a los bancos comerciales (con garantías financieras, seguimiento, capacitación, desarrollo tecnológico e innovación y capitalización), posibilitando la democratización del crédito bien sea con facilidades del préstamo de estas con sus recursos o con fondos del Banco de la República vía constitucional ante fallas del mercado financiero.

De manera formal, se puede establecer que es la Ley 590 (2000, art. 39) quien determina lo que es el microcrédito en Colombia, al plantear "con el fin de estimular las actividades de microcrédito, entendido como el sistema de financiamiento a microempresas, dentro del cual el monto máximo por operación de préstamo es de veinticinco (25) salarios mínimos mensuales legales vigentes..." (p. 8).

En ampliación a la definición de microempresa, se da un ajuste con la Ley 905 (2004), que establece como microempresa a toda unidad de explotación económica, realizada por una persona natural o jurídica, en actividades empresariales, agropecuarias, industriales, comerciales o de servicios, rural o urbana, cuya planta de personal no supere los diez (10) trabajadores o sus activos totales, excluida la vivienda, sean inferiores a quinientos (500) salarios mínimos legales mensuales vigentes.

Posteriormente, mediante el Decreto 3078 (2006) del Ministerio de Hacienda y Crédito Público, se crea el Programa de Inversión Banca de las Oportunidades, con objeto de promover el acceso al crédito y los demás servicios financieros a las familias de menores ingresos, micro, pequeñas y medianas empresas y emprendedores. Es así como, a partir de ese año se ve una política decidida de inclusión financiera:

Desde 2006 el Gobierno Nacional ha emprendido una estrategia con el apoyo de la política de Banca de las Oportunidades, lo que ha permitido la ejecución de diversas iniciativas de inclusión financiera como, ampliar la cobertura geográfica regional y crear productos de ahorro simplificados con menores costos y requisitos de acceso. Igualmente le dio un impulso significativo al otorgamiento del crédito, mediante la diferenciación del límite máximo de la tasa de interés del microcrédito (Comisión Intersectorial para la inclusión financiera, CIEEF, 2016, p. 4)

Esta iniciativa ha permitido avanzar en la política de inclusión financiera. Antes de la Ley 590 (2000), las fuentes de financiación de las microempresas se limitaban a agiotistas y a las pocas entidades no bancarias especializadas en este segmento empresarial (Avendaño, 2006), ahora los microempresarios disponen de una oferta de financiación más variada. Según el Banco de la República y Asomicrofinanzas, 
en la actualidad, "existen más de 50 entidades entre bancos universales, bancos de nicho, ONG e instituciones microfinancieras" (Estrada \& Hernández, 2019, p. 28) dirigidas al microcrédito.

En el año 2007, el Gobierno Nacional autoriza a la Supersociedades para implementar la certificación del interés bancario corriente por modalidad, separando el microcrédito del crédito de consumo y ordinario (Decreto 519, 2007).

Para el año 2015, con el Decreto 2338, el Ministerio de Hacienda y Crédito Público creó la Comisión Intersectorial para la Inclusión Financiera (CIEEF), cuya principal función es orientar, asesorar y recomendar la adopción y ejecución de las medidas y políticas tendientes a desarrollar la inclusión financiera en el país.

En adición, cabe destacar que el entramado institucional y normativo aunado con el desarrollo del sector microfinanciero, han creado un escenario adecuado para la transformación de entidades que intentan masificar sus servicios. Se han observado procesos en los que las ONG e instituciones financieras no formales se transforman en banca comercial (upgrading) y procesos en los que la banca tradicional incursiona en ofrecer servicios microfinancieros (downscaling).

En torno a los usuarios del microcrédito en Colombia, las cifras para el periodo 2008-2015, establecen un aumento considerable en el número de personas con microcrédito, al pasar de 700 mil personas en el año 2008 a 3,5 millones en el año 2015, no obstante, el acceso a crédito de las micro y pequeñas empresas sigue rezagado (CIEEF, 2016).

Por su parte, el estudio desarrollado por Asociación Bancaria y de Entidades Financieras de Colombia para el periodo 2009-2015, afirma que el microcrédito ha tenido un alto crecimiento, dada la entrada de nuevos jugadores al mercado en el último año de dos bancos especializados en dicho segmento, Banco Mundo Mujer y Bancompartir, posibilitando que la cartera de microcrédito creciera un 20\% anual, sumando para el periodo 2009-2015 un 187\% (Asobancaria, 2016).

No obstante, de este alto crecimiento, el estudio determinó en la evolución de la composición de la cartera bruta del sector bancario, que el microcrédito solo representa el 3\% de la misma en promedio para todo el periodo, considerablemente alejado del crédito comercial por encima del 60\% para el periodo. De las 25 entidades participantes en el sector bancario colombiano en el año 2015, 16 otorgaron microcréditos y de estas, 5 entidades financieras tienen una participación del microcrédito mayor al 50\% en el crédito otorgado (Asobancaria, 2016).

En torno al microcrédito en el ámbito regional, se puede afirmar a partir del estudio realizado por Ramos y Madroñero (2010), sobre el papel del microcrédito en la actividad formal empresarial en el casco urbano del municipio de Pasto año 2010, que los microempresarios no cuentan con los recursos propios suficientes para financiar la totalidad de las actividades empresariales, siendo el microcrédito una fuente importante de recursos para el 89,67\%, que lo utilizaron como fuente de financiamiento.

Otro estudio importante del microcrédito en la región, es el de Delgado, Arboleda y Paredes (2015), denominado "Microcrédito: opción para el microempresario nariñense", el cual establece, que de las empresas encuestadas en Pasto en el año 2013 que afirmaron tener financiamiento, el 28,9\% correspondió a microcréditos, 
y que dichos servicios fueron cubiertos por las 14 entidades financieras presentes en la ciudad.

Para el año 2016, según la Banca de las Oportunidades (2016), diferentes entidades microfinancieras, han hecho presencia en Pasto y han mantenido un crecimiento importante de sus actividades, registrándose un total de 20 entidades financieras, con 61 oficinas. Para dicho año, en Nariño el microcrédito total registró $\$ 814$ mil millones de pesos de una cartera total de $\$ 3.524$ mil millones, representando el 23,10\%, un nivel menor del promedio nacional del 29,53\%. Se destaca para este año el crecimiento del microcrédito en el departamento del 8,4\% con respecto al año 2015, superior al promedio nacional del 6,7\% (Banco de la República, 2017a).

El análisis realizado también por el Banco de la República (2014) para la economía regional en el periodo 2011-2013, establece que hay un crecimiento constante del microcrédito en dicho periodo, pasando de $\$ 373$ mil millones de pesos en 2011 a $\$ 468$ mil millones en el 2012 y a $\$ 551$ mil millones en el año 2013 , lo que demuestra un crecimiento en el año 2012 del 25,4\% y del 17,8\% en el año 2013, teniendo niveles mayores al ámbito nacional para los años 2012 y 2013, de 19,8\% y 17,3\%, respectivamente. Como afirma el mismo estudio, el crecimiento del crédito en Nariño se viene presentando de manera continua desde la recuperación de la crisis del 2008, hasta mantener estabilidad en los últimos períodos, inclusive con aumentos superiores al promedio nacional.

A pesar de este crecimiento, el entorno regional muestra las dificultades del acceso al microcrédito por parte de los microempresarios, que como indican en su estudio Delgado, Arboleda y Paredes (2015), el 76\% de los microempresarios entrevistados manifestó utilizar fuentes de financiación externas, de los cuales solo el 69,9\% proviene de oferentes del sector financiero, cuyo mayor porcentaje lo representan los bancos con el 50,30\% y el restante $19,60 \%$ son ONG. De igual manera, llama la atención en las condiciones microcrediticias de la región, el establecer que el 60\% de las entidades bancarias y el 20\% de las ONG, niegan créditos a los microempresarios por reportes en centrales de riesgo, falta de experiencia comercial y experiencia crediticia, entre otras causas.

En cuanto a la participación de las microempresas en el sector manufacturero en el municipio de Pasto, el registro de Cámara de Comercio de Pasto (2016), establece que el 97,16\% de las empresas registradas del sector manufacturero son microempresas, lo que refleja la importancia de la microempresa en el sector.

\section{Aspectos MetodolóGicos}

La investigación se desarrolló con un enfoque cuantitativo, bajo un tipo de estudio descriptivo, donde se realizó un análisis de las principales variables que determinan las características del microcrédito en el año 2016. La información se obtuvo por medio de una encuesta estructurada, diseñada con preguntas que posibilitan determinar las características y percepciones de los microempresarios del sector manufacturero, ajustadas con base en las preguntas relacionados a los objetivos planteados inicialmente, para el desarrollo del trabajo de investigación: 
1. Determinar las características de las microempresas usuarias.

2. Determinar las características del microcrédito obtenido.

3. Determinar el nivel de satisfacción de los microcréditos obtenido.

El resumen de la matriz de operatividad de variables, recoge la estructura de las variables utilizadas en la aplicación de la encuesta, dando respuesta a los objetivos planteados en la investigación (Anexo 1).

Con la información de la Cámara de Comercio de Pasto (2016) se identificó la presencia de 1759 empresas manufactureras, de las cuales 1709 eran microempresas del sector, éstas se constituyeron en la población total para la determinación de una muestra para poblaciones finitas con un error máximo aceptable del 5\% y un nivel deseado de confianza del $95 \%$, de tal manera que la muestra representativa estuvo constituida por 315 microempresas de la industria manufacturera en la ciudad de Pasto. El instrumento de encuesta se aplicó de forma ponderada de acuerdo al Código Industrial Internacional Uniforme (CIIU) año 2016 (Anexo 2).

La información contenida en la base de datos del registro de las Empresas en la Cámara de Comercio de Pasto (2016), permitió seleccionar las unidades de muestreo en forma aleatoria garantizando que todas las microempresas tuvieran la misma probabilidad de ser encuestadas al interior de cada subsector y además facilitó ubicar las empresas con su dirección para la adecuada aplicación de las encuestas de manera presencial. De acuerdo a la afirmación de Canales (2006), la confiabilidad y validez de los resultados de la investigación, se reflejan en todo el proceso, siendo lo primero visible desde la calidad de la muestra como la presencia del encuestador, y lo segundo, de la relación de correspondencia entre la medición y lo medido.

\section{Resultados}

\section{Microcrédito en el sector manufacturero del municipio de Pasto}

Los resultados de la encuesta aplicada a las microempresas del sector industrial manufacturero de Pasto en el año 2016, determinaron dos ámbitos generales, uno relacionado con las características de las microempresas según clasificación de acceso al microcrédito, y otro referente a los aspectos del microcrédito como la percepción de los usuarios en torno a la satisfacción, las dificultades y la renovación del servicio.

\section{Características de las microempresas usuarias}

Con base en la información obtenida, se diferencian tres grupos en torno a la relación empresa-microcrédito, encontrando que la mayor proporción, el 64,76\% en su tiempo de operación solicitó algún microcrédito, mientras que el 34,24\% no lo solicitó. De este último grupo se desprenden las dos categorías siguientes, el 19,37\% no solicitó microcrédito porque no lo ha necesitado, es decir que estos establecimientos cuentan con los recursos financieros económicos suficientes para apalancar su actividad y cubrir el capital de trabajo necesario. Por su parte, el 15,87\% restante, no solicitó microcrédito 
porque tiene una percepción negativa sobre este, lo cual está asociado principalmente a los altos costos y a dificultades en los trámites.

De acuerdo con lo anterior, se evidencia la presencia de dos fenómenos particulares como son la exclusión y la autoexclusión financiera, el primer fenómeno se debe a condiciones particulares del mercado financiero, como establecen Beltrán y Gómez (2017), De la Torre (2018) y Torre, Sainz, Sanfilippo \& López (2012), donde las causas que impiden el fácil acceso al sistema financiero son: la falta de documentos legales, baja capacidad de pago, edad (personas mayores o muy jóvenes), falta de educación financiera o crisis económica, entre otras; mientras que, el segundo fenómeno puede deberse principalmente a la percepción particular del usuario, como por ejemplo malas experiencias o mala atención en entidades de crédito.

Al momento de realizar la caracterización de cada grupo, se encontró que no existen diferencias significativas entre ellos, por el contrario, sus características corresponden a la descripción general de una microempresa manufacturera, es decir, más del 90\% se encuentran constituidas como personas naturales, alrededor del 50\% tienen antigüedad de entre 1 y 12 años y tienen entre 1 y 3 empleados; el manejo de la contabilidad se hace principalmente a través del libro de registro diario de operaciones (aproximadamente el 45\%), y casi el 60\% de las empresas desarrollan sus operaciones en infraestructuras bajo la modalidad de arrendamiento.

Otro elemento de estudio, es lo relacionado con la administración y dirección de los establecimientos, al respecto, la investigación arrojó como resultado que más del 80\% de los establecimientos manufactureros son administrados por el propietario, esto indica que los propietarios prefieren dirigir y afrontar las necesidades de su empresa. Del total de los administradores, más del 60\% son hombres, el nivel educativo predominante es la secundaria, la edad promedio está entre los 41 y 50 años de edad y en mayor medida pertenecen a un estrato socioeconómico bajo, entre 1 y 3 .

De acuerdo a la clasificación Industrial Internacional (CIIU), la mayor parte de las microempresas del sector manufacturero hacen parte de los establecimientos dedicados a la elaboración de productos alimenticios con participación del 23,76\%, continúa en orden de participación, la confección de prendas de vestir con 12,17\%, el curtido y recurtido de cueros con $7,73 \%$ y las actividades de impresión y de producción de copias a partir de grabaciones originales con $7,62 \%$. En estas cuatro actividades se concentra el 51\% de las actividades industriales manufactureras del Municipio.

\section{Características del microcrédito obtenido}

Dentro del estudio se establece que los microempresarios no tienen claridad acerca de las tasas de interés, los tipos de cuotas e incluso los plazos que están manejando con sus microcréditos, es así como, más del 80\% de los encuestados no generaron respuestas adecuadas a dichos aspectos, lo cual supone que el manejo financiero de la microempresa puede no ser el más adecuado, ello estaría impidiendo un buen uso del apalancamiento financiero. Lo anterior refleja una débil educación financiera de sus administradores, situación que es común en la población colombiana en conocimientos financieros (Beltrán \& Gómez, 2017; Reddy, Bruhn \& Congyan, 2013; García, Grifoni, López \& Mejía, 2013). 
En este sentido, la educación financiera asume un rol destacado, ya que el uso de adecuadas herramientas financieras puede marcar la diferencia entre el surgimiento o hundimiento de una empresa, es así como:

La educación financiera permite el acceso de las personas a información y herramientas sobre el funcionamiento del complejo mundo de la economía y las finanzas; y su incidencia e importancia en la vida diaria, otorgando la confianza que da el conocimiento, en la toma de decisiones (Ruíz, 2011, p. 1).

Frente a eso, es preciso mencionar que, en el país se han introducido acciones de gobierno tendientes a fortalecer la educación financiera; la más reciente de ellas es:

[...] la Estrategia Nacional de Educación Económica y Financiera "Alianza de Educación Económica y Financiera duradera para los colombianos", orientada en coordinar el diseño e implementación de iniciativas y programas de Educación Económica y Financiera (EEF) públicos y privados y promover la adopción de herramientas y canales que faciliten la divulgación de su contenido (CIEEF, 2017, p. 28).

De otra parte, se encontró que el 80,39\% de las empresas prefirió solicitar su microcrédito a bancos; le siguen las cooperativas y las entidades microcrediticias y finalmente los prestamistas gota a gota, familiares o amigos, entre otros.

Con relación a los montos solicitados, de acuerdo con la información suministrada por los encuestados, se tiene que la mayor concentración está ubicada en préstamos entre uno y cinco millones de pesos $(43,48 \%)$, adicionalmente, el plazo que prefieren lo empresarios para liquidar este tipo de obligaciones se encuentra entre uno y cinco años representando este plazo el 75\% del total (Tabla 1).

TABLA 1.

Montos de microcrédito solicitados por la industria manufacturera en la ciudad de Pasto, año 2016.

\begin{tabular}{lcl}
\hline & Monto total & \\
\cline { 1 - 2 } Límite mínimo. & Límite máximo. & \\
$\$ 1.000 .000$ & $\$ 3.000 .000$ & 22,98 \\
$\$ 3.000 .001$ & $\$ 5.000 .000$ & 20,5 \\
$\$ 5.000 .001$ & $\$ 12.000 .000$ & 18,63 \\
$\$ 12.000 .001$ & $\$ 23.000 .000$ & 18,01 \\
$\$ 23.000 .001$ & $\$ 56.000 .000$ & 19,88 \\
\hline & Total & 100 \\
\hline
\end{tabular}

Fuente: Cálculo de autores.

Con respecto al análisis de las garantías y requisitos solicitados para acceder al microcrédito, se establece que estas son de diferentes fuentes. Sólo un 7\% de los microempresarios estableció que no le exigieron ninguna garantía. Entre las garantías más exigidas están las tradicionales como las propiedades $(34,64 \%)$, seguidas por los codeudores $(22,88 \%)$ y otras garantías de diferente índole entre las cuales se destacan: el registro en Cámara de Comercio, la experiencia crediticia, balances de la empresa, clientes y Datacrédito (Figura 1). 


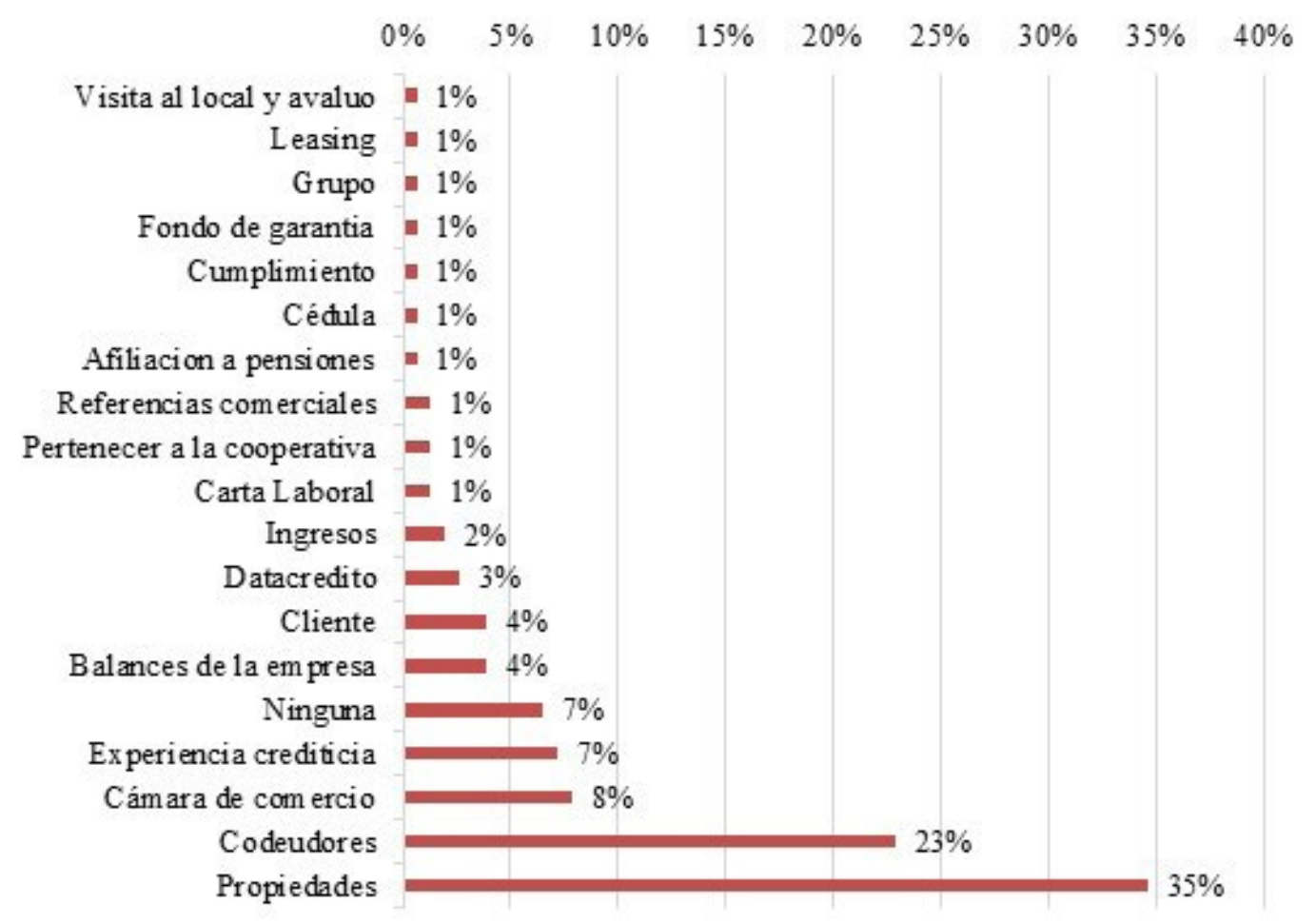

Figura 1. Garantías y requisitos solicitados para acceder al microcrédito. Fuente: Cálculo de autores.

Sobre los usos específicos a los que se destinan los microcréditos en las microempresas, se identificó lo siguiente: de un lado, cerca del $92 \%$ de los usuarios de microcrédito afirmaron haber utilizado el microcrédito sobre la actividad económica, mientras que el 8\% restante dijeron lo contrario. Sin embargo, debe tenerse en cuenta que, el bajo riesgo moral del lado del demandante percibido en el estudio, puede ser efecto de procesos más eficaces tanto en la consecución de información como en la evaluación del otorgamiento de microcréditos por las entidades.

De otro lado, al preguntar sobre el destino principal dado al préstamo, los encuestados destacaron que el microcrédito se dirigió principalmente a capital de trabajo, activos fijos, mejoramiento de vivienda y pago de obligaciones (Tabla 2).

TABLA 2.

Principal destino del microcrédito recibido. Pasto, 2016.

\begin{tabular}{ll}
\hline \multicolumn{1}{c}{ Destino microcrédito } & \multicolumn{1}{c}{$\%$} \\
\hline Capital de trabajo & 67,49 \\
Activos fijos & 12,88 \\
Mejoramiento de Vivienda & 9,2 \\
Pago de obligaciones & 6,13 \\
Consumo & 3,07 \\
Educación & 0,61 \\
Otro & 0,61 \\
\hline
\end{tabular}

Fuente: Cálculo de autores. 
$\mathrm{Al}$ respecto, se aduce que las necesidades de financiamiento de corto plazo (capital de trabajo y pago de obligaciones) para las microempresas han primado sobre las de largo plazo. Esto parece mostrar que la expansión y diversificación productiva de las microempresas de la industria manufacturera del municipio ha sido escasa o reducida. Así, la débil expansión económica de las microempresas estaría respondiendo tanto a su baja capacidad administrativa (60\% de los microempresarios tienen un nivel educativo inferior o igual a bachillerato) como a las condiciones macroeconómicas del municipio (bajo aporte de la industria manufacturera al valor agregado municipal $^{1}$ y la tendencia de desindustrialización de la economía colombiana) (Ortiz, 2009).

\section{Nivel de satisfacción del microcrédito obtenido}

En términos de satisfacción del microcrédito y al servicio recibido de las entidades prestamistas, por lo general, los usuarios afirmaron que fue oportuno, suficiente y de fácil acceso. Además, cerca del $65 \%$ estuvieron satisfechos con el servicio y trato recibido. No obstante, en cuestión del costo del microcrédito, la mitad de usuarios señalaron que el servicio fue costoso (Tabla 3).

TABLA 3.

Percepción de los usuarios acerca de las características del microcrédito.

\begin{tabular}{|c|c|c|c|c|c|}
\hline Característica & $(\%)$ & $(\%)$ & $(\%)$ & $(\%)$ & $(\%)$ \\
\hline \multirow{2}{*}{ Oportunidad } & & & Oportuno & Inoportuno & Total \\
\hline & & & 97,56 & 2,44 & 100 \\
\hline \multirow{2}{*}{ Suficiencia } & & & Suficiente & Insuficiente & Total \\
\hline & & & 78,4 & 21,6 & 100 \\
\hline \multirow{2}{*}{ Acceso } & & Fácil & Medianamente fácil & Difícil & Total \\
\hline & & 67,48 & 23,93 & 8,59 & 100 \\
\hline \multirow{2}{*}{ Costo } & & Barato & Normal & Costoso & Total \\
\hline & & 7,98 & 44,79 & 47,24 & 100 \\
\hline \multirow{2}{*}{ Trato recibido } & & Excelente & Normal & Poco amable & Total \\
\hline & & 64,6 & 34,16 & 1,24 & 100 \\
\hline \multirow{2}{*}{ Satisfacción } & Mucho & Regular & Poco & Nada & Total \\
\hline & 69,94 & 25,77 & 3,68 & 0,61 & 100 \\
\hline
\end{tabular}

Fuente: Cálculo de autores.

Estos resultados tienen relación con las quejas recibidas por las entidades oferentes de microcrédito en los reportes trimestrales de la situación del microcrédito de Colombia, que hace el Banco de la República (2015, 2016 y 2017b), cuyas quejas de

${ }^{1}$ De acuerdo con la ficha territorial de Pasto de la Dirección Nacional de Planeación, el sector secundario, que comprende a los subsectores de industria manufacturera y construcción, representó el 16,17 \% del valor agregado municipal en 2017 (Dirección Nacional de Planeación-DNP, s.f). 
mayor frecuencia son: las altas tasas de interés, la cantidad de crédito insuficiente, la aprobación de crédito difícil; aunque, en ese conjunto, recientemente han adquirido relativa importancia las quejas sobre los plazos cortos y las comisiones altas.

Adicionalmente, al preguntar acerca de las dificultades que encontraron en las etapas del servicio recibido, se encontró que el 45,34\% de los usuarios declararon no haber tenido dificultades en acceder al microcrédito, mientras que el 54,66\% expresaron tener dificultades relacionadas con los trámites, los requisitos de solicitud y los costos de otorgamiento (Tabla 4).

Estos aspectos según la CIEEF (2016), desincentivan el uso de microcrédito en las firmas de tamaño reducido. Adicional a ello, si se observa la valoración de los usuarios respecto a la gestión de la entidad prestamista sobre la obligación microcrediticia, se puede destacar que gran parte de los usuarios percibieron la gestión de cobro, la renovación del microcrédito y la presentación de alternativas de solución a dificultades presentadas con su obligación como normal o buena (Tabla 5). En cambio, cerca de la mitad de usuarios no vieron ninguna gestión en cuanto a interés por conocer el buen desempeño de su actividad económica y al control de la inversión.

TABLA 4.

Dificultades encontradas en las etapas de microcrédito.

\begin{tabular}{ll}
\hline \multicolumn{1}{c}{ Etapas } & \multicolumn{1}{c}{$\%$} \\
\hline Acceso a información. & 4,97 \\
Contacto con el asesor. & 3,11 \\
Reunir los requisitos. & 24,84 \\
Estudio y aprobación. & 7,45 \\
Desembolso. & 3,11 \\
Seguimiento. & 3,73 \\
Pago de las cuotas. & 3,11 \\
En dos etapas. & 2,48 \\
En más de tres etapas. & 1,86 \\
\hline \multicolumn{2}{c}{ Ninguna } \\
\hline
\end{tabular}

Fuente: Cálculo de autores.

De igual modo, con el propósito de aproximarse el grado de fidelización de los clientes en las entidades financieras y microfinancieras, al indagar sobre el deseo de continuar utilizando el servicio, se encontró en el estudio que el 67,48\% de los usuarios desearían seguir tomando el microcrédito, mientras que el 32,52\% señalaron que no. La respuesta de seguir utilizando el servicio estaría soportada en el menor costo en comparación con el crédito informal, además, como se ha manifestado, hay gran satisfacción por el servicio prestado².

\footnotetext{
${ }^{2}$ Utilizando el estadístico de asociación Chi-cuadrado, se encontró que, la percepción del costo del microcrédito como la satisfacción del servicio están ligados con el deseo del usuario de seguir utilizando el microcrédito (Anexo 3)
} 
TABLA 5.

Gestión observada en el acompañamiento

de la obligación financiera de la entidad crediticia.

\begin{tabular}{lrrc}
\hline \multicolumn{1}{c}{ Tipo de acompañamiento } & Ninguno & Normal & Bueno \\
\cline { 2 - 4 } & $\%$ & $\%$ & $\%$ \\
\hline Renovación de su microcrédito. & 34,57 & 43,21 & 22,22 \\
Gestión de cobro. & 16,77 & 52,17 & 31,06 \\
$\begin{array}{l}\text { Alternativas de solución a dificultades presentadas con su } \\
\text { obligación. }\end{array}$ & 16,88 & 28,75 & 54,38 \\
$\begin{array}{l}\text { Interés por conocer el buen desempeño de su actividad } \\
\text { económica. }\end{array}$ & 47,53 & 24,69 & 27,78 \\
Control de la inversión. & 44,79 & 20,25 & 44,79 \\
\hline
\end{tabular}

Fuente: Cálculo de autores.

Por el contrario, quienes no continuarán utilizando el microcrédito, manifestaron que la razón principal para tomar esta decisión era las altas tasas de interés (61,54\%), le siguen en menor proporción que no lo consideraban necesario $(13,46 \%)$, los montos aprobados eran insuficientes (7,69\%) y los requisitos de aprobación eran muy exigentes (3,85\%), entre otras. Es lógico esperar que las tasas para microcréditos sean más altas que las del crédito tradicional, dada la calidad crediticia del solicitante en ámbitos de un mayor riesgo como es la microempresa (Rodríguez \& Venegas, 2012).

\section{CONCLUSiOnes}

Determinando las características empresariales, se encontró que la mayoría de las empresas encuestadas y usuarias de microcrédito en el sector manufacturero del municipio de Pasto, tienen una experiencia en su funcionamiento de 1 a 12 años, su actividad económica la desarrollan con la participación promedio de 1 a 3 trabajadores, llevan un sistema básico de contabilidad (52\%), aunque otra porción considerable de empresas no la lleva (22\%), generalmente no cuentan con espacios propios para su funcionamiento, por lo que recurren a la figura del arrendamiento y más del $84 \%$ de estas microempresas, son administradas por los propietarios, los cuales se caracterizaron por ser principalmente del género masculino, con edades entre los 40 y 60 años, y con niveles de educación media o secundaria.

En torno al uso del microcrédito, se determinó que el 64,76\% de las microempresas de la industria manufacturera hicieron uso del microcrédito, los cuales se caracterizaron por ser de bajo monto (el 43,48\% de este grupo solicitó entre $\$ 1$ y $\$ 5$ millones y el $18,63 \%$ solicitó entre $\$ 5$ y $\$ 12$ millones), de corto y mediano plazo (entre 1 a 5 años) y de tipo formal. Si bien, lo anterior refleja una mayor preferencia por el microcrédito formal, los montos promedios aprobados y los créditos a corto y mediano plazo, reflejan un bajo aprovechamiento del microcrédito en la industria manufacturera, pues son insuficientes para generar un impacto significativo en el sector. En 
ese sentido, el diseño de productos micro crediticios debería contemplar la heterogeneidad del sector microempresarial (actividades de subsistencia y de rentabilidad) y, además, integrar incentivos que permitan expandir y desarrollar las microempresas que cuentan con potencial de crecimiento a través de la financiación de activos fijos que mejoren su productividad.

De otro lado, la investigación reveló debilidades en la educación financiera de los microempresarios del sector, al encontrar inseguridad y poca claridad al momento de responder preguntas acerca de las tasas de interés, los saldos de su deuda, los tipos de cuotas establecidas con la entidad financiera, entre otros. Esta situación podría estar limitando su capacidad de toma de decisiones financieras acertadas y responsables, estimulando, a su turno, la autoexclusión financiera. Frente a este tema, es importante tener en cuenta que el consumidor financiero requiere tener un mayor y mejor acceso a la educación financiera, esto con el fin de que sea capaz de aprovechar las oportunidades que el sistema financiero le ofrece, principalmente en lo referente a desarrollo de empresa, pudiendo invertir los recursos otorgados no solo en capital de trabajo sino también en innovación y desarrollo.

Ahora bien, en relación al uso del microcrédito se establece, que la presencia de riesgo moral es baja, dado que el $92 \%$ de los usuarios afirmaron haber utilizado el microcrédito sobre la actividad económica. Esto es efecto de la adecuada información y evaluación empresarial para el otorgamiento del crédito. De igual manera, se determina que la destinación principal del microcrédito fue al capital de trabajo (67\%), activos fijos (13\%), mejoramiento de vivienda (9\%) y pago de obligaciones (6\%), lo cual refleja que el crédito se destina a la empresa y a la solución de problemas financieros de corto plazo.

En cuanto a la percepción de los usuarios respecto al servicio microcrediticio, los microempresarios han manifestado sentirse satisfechos con el servicio y el trato recibido por la entidad oferente y han percibido al microcrédito como suficiente, oportuno y de fácil acceso; sin embargo, el $47 \%$ de ellos han percibido al microcrédito como costoso y el 4\% manifestó no estar satisfecho con el servicio. Además, la investigación encontró que se presentan dificultades en los trámites, garantías y requisitos de aprobación, se destaca como las principales dificultades: la tenencia de propiedades, la solicitud de codeudores, la experiencia crediticia y la información financiera y contable de la unidad productiva. Por ello es necesario, que las entidades continúen encontrando formas eficaces e innovadoras que reduzcan los riesgos de operación del microcrédito en aspectos como garantías, bajos niveles de activos, vacíos de información empresarial, comercial y contable; que posibiliten hacer del microcrédito un producto más atractivo y asequible en precio y calidad.

Paralelamente, en cuanto a la percepción de los usuarios frente al acompañamiento de la obligación financiera realizada por la entidad ofertante, estos, efectivamente, han visto acompañamiento en la gestión de cobro, la renovación del microcrédito y en la presentación de alternativas de solución a dificultades presentadas con su obligación, pero no en los aspectos de interés como por ejemplo: conocer el buen desempeño de su actividad económica, realizar el control de la inversión, verificar la incidencia en sus condiciones de vida, entre otros. 
Finalmente, en torno a la intención de continuar accediendo a los servicios de microcrédito, el 67\% de las microempresas que hizo uso de este servicio financiero manifestó su interés de seguir haciéndolo. Por su parte, el 33\% restante, afirmó no continuar haciendo uso del microcrédito con base en sus experiencias pasadas y actuales, explicando sus razones en las altas tasas de interés, en la insuficiencia de los montos aprobados, en la exigencia de los requisitos para aprobación y, por último, porque algunos ya no lo consideraban necesario.

\section{Reconocimientos y Agradecimientos}

El artículo surge como resultado del proyecto de investigación con el mismo nombre, financiado por la Universidad de Nariño a través del Sistema de Investigaciones en la Convocatoria de investigación Docente 2015, el cual fue realizado por el Grupo de Investigación Coyuntura Económica y Social CES.

\section{REFERENCIAS}

Asobancaria. (2016). La banca colombiana en 2015. [Informe]. Bogotá, D.C.: Asobancaria. Recuperado de https:/www.asobancaria.com/wp-content/uploads/2016/06/ Informe-de-Tipificaci\%C3\%B3n-2015-Version-Web.pdf

Avendaño, H. (2006). ¿Es demasiado costoso el microcrédito en Colombia? Carta Financiera de ANIF. Recuperado de https:/www.findevgateway.org/sites/default/ files/publications/files/mfg-es-documento-es-demasiado-costoso-el-microcreditoen-colombia-5-2006.pdf

Banca de las Oportunidades. (2016). Coberturas. [Online]. Disponible en http://bancadelasoportunidades.gov.co/es/cobertura

Banco de la República. (2017a). Boletín económico regional. IV trimestre de 2016. Suroccidente. Valle del Cauca/Nariño/Cauca/Putumayo. Bogotá, D.C.: Banco de la República. Disponible en https://repositorio.banrep. gov.co/bitstream/handle/20.500.12134/7792/ber_suroccidente_tri4_2016. pdf?sequence=1\&isAllowed $=y$

Banco de la República. (2017b). Reporte de la situación actual del microcrédito en Colombia, septiembre de 2017. Disponible en http://www.banrep.gov.co/es/reporte-de-la-situacion-del-microcredito-en-colombia

Banco de la República. (2016). Reporte de la situación actual del microcrédito en Colombia, septiembre de 2016. Disponible en http://www.banrep.gov.co/es/reportede-la-situacion-del-microcredito-en-colombia

Banco de la República. (2015). Reporte de la situación actual del microcrédito en Colombia, septiembre de 2015. Disponible en http://www.banrep.gov.co/es/reportede-la-situacion-del-microcredito-en-colombia

Banco de la República. (2014). Boletín económico regional. IV trimestre de 2013. Suroccidente. Valle del Cauca/Nariño/Cauca/Putumayo. Bogotá, D.C.: Banco de la República. Disponible en https://repositorio.banrep.gov.co/bitstream/handle/20.500.12134/7621/ber_suroccidente_tri4_2013.pdf?sequence=1\&isAllowed=y 
Banco de la República. (2010). Situación actual del microcrédito en Colombia: características y experiencias. [Reporte de estabilidad financiera]. Bogotá, D.C:: Finagro. Recuperado de https://www.banrep.gov.co/sites/default/files/publicaciones/archivos/Tema1_sept.pdf

Barona, B. (2004). Microcrédito en Colombia. EG/Estudios Gerenciales, (90), 79104. Disponible en https://www.icesi.edu.co/revistas/index.php/estudios_gerenciales/article/view/132

Beltrán, L. y Gómez, E. (2017). Educación financiera en estudiantes universitarios. Económicas CUC, 38(2), 101-112. https://doi.org/10.17981/econcuc.38.2.2017.08

Berger, M. (2000). Las microfinanzas: Un mercado emergente dentro de los mercados emergentes. Washington, DC: Banco Interamericano de Desarrollo. Recuperado de https://docplayer.es/17247287-Las-microfinanzas-un-mercado-emergente-dentro-de-los-mercados-emergentes.html

Cámara de Comercio de Pasto. (2016). Anuario estadístico de Registro Público 2016. San Juan de Pasto: Departamento de Planeación Institucional y Competitividad Regional. Disponible en https://www.ccpasto.org.co/?page_id=7025

Canales, M. (2006). Metodologías de investigación social. Santiago de Chile: Editorial Lom.

CIEEF. (2017). Estrategia nacional de Educación Económica y Financiera de Colombia (ENEEF). Bogotá D.C.: CIEEF. Recuperado de https://www.banrep. gov.co/sites/default/files/publicaciones/archivos/estrategia_nacional_educacion_economica.pdf

CIEEF. (2016). Estrategia Nacional de Inclusión Financiera en Colombia. Bogotá D.C.: CIEEF. Recuperado de https://www.superfinanciera.gov.co/descargas/ institucional/pubFile1030467/estrategia_nacional_inclusion_financiera.pdf

De La Torre, M. (2018). Utilización del sector financiero para el lavado de dinero: perspectiva desde la legislación ecuatoriana. Jurídicas CUC, 14(1), 145-166. https://doi.org/10.17981/juridcuc.14.1.2018.07

Delgado, B., Arboleda, M. y Paredes, M. (2015). Microcrédito: opción para el microempresario nariñense. Revista UNIMAR, 33(1), 151-163. Disponible en http://editorial.umariana.edu.co/revistas/index.php/unimar/article/view/909

Estrada, D. \& Hernández, A. (2019). Situación actual e impacto del microcrédito en Colombia. Bogotá, D.C.: Banco de la República/Asomicrofinanzas. Disponible en https://repositorio.banrep.gov.co/bitstream/handle/20.500.12134/9723/ LBR_2019-07.pdf?sequence $=8$

Garavito, D. (2016). Microcréditos: evolución y situación actual del sistema de microfinanzas en Colombia. Revista Universitas Estudiantes, (13), 49-72. Disponible en http://hdl.handle.net/10554/44433

García, N., Grifoni, A., López, J. C. \& Mejía, D. (2013). La educación financiera en América Latina y el Caribe: Situación actual y perspectivas. Serie Politicas Públicas y Transformación Productiva, (12). Caracas: CAF. Disponible en http://scioteca.caf.com/handle/123456789/379 
Giraldo, D. (2012). El microcrédito como solución al racionamiento de crédito: el comportamiento crediticio de los clientes de la "Fundación Banco Mundial de la Mujer" en la Ciudad de Cali, en el año 2009. [Trabajo de grado]. Universidad del Valle, Santiago de Cali, Colombia. Recuperado de http://hdl.handle. net/10893/3720

González, L. (Dir.) (2011). Microcréditos para combatir la pobreza. Una introducción a los conceptos básicos de microfinanzas como instrumento alternativo para la financiación del desarrollo. Valladolid: AECID/Universidad de Valladolid. Recuperado de http://cooperacion.uva.es/files/2020/05/Microcreditos_Pobreza.pdf

Gutiérrez, B. (2006). El microcrédito: dos escuelas teóricas y su influencia en las estrategias de lucha contra la pobreza. CIRIEC, (54), 167-186. Recuperado de http://ciriec-revistaeconomia.es/wp-content/uploads/07_Gutierrez_54.pdf

Ordóñez, I., y Guerra, E. (2014). Microcrédito y créditos tradicional e informal como fuentes de financiamiento: facilidad de acceso y costos del capital de trabajo. Revista Entorno, (57), 56-69. https://doi.org/10.5377/entorno.v0i57.6254

Ortiz, C. H. (2009). La desaceleración económica colombiana: se cosecha lo que se siembra. Revista Economía Institucional, 11(21), 107-137. Disponible en https:// revistas.uexternado.edu.co/index.php/ecoins/article/view/371

Ramos, A. \& Madroñero, N. (2011). El papel del microcrédito en la actividad formal empresarial en el casco urbano del municipio de Pasto 2010. Tendencias, 12(2), 58-81. Disponible en https://revistas.udenar.edu.co/index.php/rtend/article/view/528

Reddy, R., Bruhn, M. \& Congyan, T. (2013). Capacidades financieras en Colombia: resultados de la encuesta nacional sobre comportamientos, actitudes y conocimientos financieros. Washington DC: BIRF/Banco Mundial. Disponible en https://www.bancomundial.org/es/country/colombia/publication/national-survey-financial-capabilities-colombia

República de Colombia. Congreso de la República. (02 de agosto de 2004). Por medio de la cual se modifica la Ley 590 de 2000 sobre promoción del desarrollo de la micro, pequeña y mediana empresa colombiana y se dictan otras disposiciones. [Ley 905]. Diario Oficial: 45628. Disponible en http://www.secretariasenado. gov.co/senado/basedoc/ley_0905_2004.html

República de Colombia. Congreso de la República. (10 de julio de 2000). Por la cual se dictan disposiciones para promover el desarrollo de las micro, pequeñas y medianas empresas. [Ley 590]. DO: 44078. Disponible en https://www.funcionpublica.gov.co/eva/gestornormativo/norma.php?i=12672

República de Colombia. DANE. (31 de enero de 2012). Clasificación de Actividades Económicas. [Resolución 066]. CIIU. Rev. 4 A.C. Recuperado de: https://www. dane.gov.co/files/sen/nomenclatura/ciiu/normatividad/Resolucion066_2012. pdf

República de Colombia. DNP. (s.f.). Terridata. [Online]. Disponible en https://terridata.dnp.gov.co/index-app.html\#/perfiles/52001 
República de Colombia. Presidencia de la República. (3 de diciembre de 2015). Por el cual se crea la Comisión Intersectorial Financiera. [Decreto 2338]. DO: 49715. Recuperado de http:/wp.presidencia.gov.co/sitios/normativa/decretos/2015/Decretos2015/DECRETO\%202338\%20DEL\%203\%20DE\%20DICIEMBRE\%20 DE\%202015.pdf

República de Colombia. Presidencia de la República. (26 de febrero de 2007). Por el cual se determinan las distintas modalidades de crédito cuyas tasas deben ser certificadas por la Superintendencia Financiera de Colombia y se dictan otras disposiciones. [Decreto 519]. DO: 46554. Disponible en https://diario-oficial. vlex.com.co/vid/decreto-352546190

República de Colombia. Presidencia de la República. (8 de septiembre de 2006). Por el cual se crea el Programa de Inversión Banca de las Oportunidades. [Decreto 3078]. DO: 46388. Disponible en http://www.suin.gov.co/viewDocument. asp?id=1780311

Ricardo, D., Arango, L. \& Taboada, R. (2020). Microcrédito y pobreza: su relación con el desarrollo endógeno local. Económicas CUC, 41(2), 237-252. https://doi. org/10.17981/econcuc.41.2.2020.Econ.5

Rodríguez, M. (2010). El Microcrédito. Una mirada hacia el concepto y su desarrollo en Colombia. [Tesis de maestría]. Universidad Nacional de Colombia, Bogotá, D.C., Colombia. Disponible en https://repositorio.unal.edu.co/handle/ unal/70001

Rodríguez, A. \& Venegas, F. (2012). Racionamiento de crédito: perspectiva de la Nueva Economía Keynesiana. Problemas del desarrollo, 43(171), 31-51. http:// dx.doi.org/10.22201/iiec.20078951e.2012.171.33487

Ruíz, H. (2011). Conceptos sobre educación financiera. Observatorio de la Economía Latinoamericana, (144). Disponible en http://www.eumed.net/cursecon/ ecolat/mx/2011/hrr.htm

Salazar, A., Martínez, D. \& Giraldo, M. (2015). Crecimiento del microcrédito en Colombia en los años 2010-2014. [Trabajo de grado]. Universidad de Medellín, Medellín, Colombia. Disponible en http://hdl.handle.net/11407/2181

Supersociedades. (2016). Desempeño del sector de manufactura años 2013-2015. [Informe]. Bogotá D.C.: Supersociedades. Recuperado de https://www.supersociedades.gov.co/delegatura_aec/estudios_financieros/Documents/Sector\%20 Real\%20Economia/EE-\%20Sector\%20Manufactura-\%202016\%20VII\%2025. pdf

Torre, B., Sainz, I., Sanfilippo, S. \& López, C. (2012). Guía sobre microcréditos. Santander: Universidad de Cantabria. Recuperado de http://www.ocud.es/es/ files/doc851/guiamicrocreditosmail.pdf 


\section{BIODATA}

Marco Antonio Burgos Flórez es Economista de la Universidad de Nariño (Colombia). Magíster en Política Económica Internacional de la Universidad de Belgrano (Argentina). Especialista en Finanzas Universidad de Nariño. Docente tiempo completo del Departamento de Economía de la Universidad de Nariño. Director Grupo de Investigación Coyuntura Económica y Social-CES. Coordinador de la Maestría en Finanzas de la Universidad de Nariño. Sus intereses de revisión son: Economía, Economía internacional, Economía Colombiana. https://orcid.org/0000-0002-4343-1869

Gissela Fernanda Guerrero Díaz es Economista de la Universidad de Nariño (Colombia). Realizó sus estudios de especialización en Gerencia de proyectos en la Universidad de Nariño en convenio con la Universidad del Cauca (Colombia). Pertenece al Grupo de investigación Coyuntura Económica y Social (CES) de la Facultad de Ciencias Económicas y Administrativas de la Universidad de Nariño. Sus intereses de revisión son: Desarrollo económico regional, Economía agraria y de los recursos naturales, bienestar y pobreza. https://orcid.org/0000-0002-5596-1947

Harleth Fabricio Mier Goyes es Economista de la Universidad de Nariño (Colombia). Investigador en el Grupo de investigación Coyuntura Social y EconómicaCES, de la Universidad de Nariño. Pertenece al Grupo de investigación Coyuntura Social y Económica-CES de la Universidad de Nariño. Sus intereses de revisión son: Desarrollo económico regional, microfinanzas y desigualdad. https://orcid.org/00000002-6777-863X

Leticia Rodríguez López es Economista de la Universidad de Nariño (Colombia). Especialista en Gerencia del Talento Humano de la Universidad Manuela Beltrán (Colombia). Especialista en Finanzas de la Universidad de Nariño. Pertenece al Grupo de investigación Coyuntura Económica y Social (CES) de la Facultad de Ciencias Económicas y Administrativas de la Universidad de Nariño. Sus intereses de revisión son: Economía, finanzas, talento humano, seguros. https://orcid.org/00000002-6593-1397 


\section{AnEXos}

Anexo 1.

Resumen de la matriz de operacionalización de variables.

\begin{tabular}{|c|c|c|c|}
\hline Objetivo & & Variables & Categorias \\
\hline \multirow{5}{*}{$\begin{array}{l}\text { Determinar las } \\
\text { características de las } \\
\text { microempresas usuarias }\end{array}$} & \multicolumn{2}{|c|}{ Actividad económica. } & Nominal \\
\hline & \multicolumn{2}{|l|}{ Experiencia. } & Numérica \\
\hline & \multicolumn{2}{|l|}{ Numero empleados. } & Numérica \\
\hline & \multicolumn{2}{|l|}{ Tipo Contabilidad. } & Nominal \\
\hline & $\begin{array}{l}\text { Características } \\
\text { del propietario y/o } \\
\text { gerente: }\end{array}$ & $\begin{array}{l}\text { Edad } \\
\text { Género } \\
\text { Nivel Educativo } \\
\text { Estrato Socioeconómico }\end{array}$ & $\begin{array}{l}\text { Numérica } \\
\text { Nominal } \\
\text { Ordinal } \\
\text { Ordinal }\end{array}$ \\
\hline \multirow{10}{*}{$\begin{array}{l}\text { Determinar las } \\
\text { características del } \\
\text { microcrédito obtenido }\end{array}$} & \multicolumn{2}{|c|}{ Otorgante del microcrédito. } & Nominal \\
\hline & \multicolumn{2}{|c|}{ Monto total solicitado. } & Numérica \\
\hline & \multicolumn{2}{|c|}{ Monto total aprobado. } & Numérica \\
\hline & \multicolumn{2}{|c|}{ Valor y periodicidad de las Cuotas. } & Numérica \\
\hline & \multicolumn{2}{|l|}{ Plazos. } & Nominal \\
\hline & \multicolumn{2}{|l|}{ Tasa de interés. } & Numérica \\
\hline & \multicolumn{2}{|c|}{ Garantías y requisitos solicitados. } & Nominal \\
\hline & \multicolumn{2}{|c|}{ Otros servicios financieros usados. } & Nominal \\
\hline & \multicolumn{2}{|c|}{ Destino y uso del microcrédito. } & Nominal \\
\hline & \multicolumn{2}{|c|}{ Resultados generados del uso del microcrédito. } & Nominal \\
\hline & \multicolumn{2}{|c|}{ Oportunidad del microcrédito. } & Nominal \\
\hline & \multicolumn{2}{|c|}{ Suficiencia en el monto. } & Nominal \\
\hline & \multicolumn{2}{|c|}{ Satisfacción con el servicio. } & Ordinal \\
\hline Determinar el nivel & \multicolumn{2}{|l|}{ Servicio al cliente. } & Ordinal \\
\hline de satisfacción de los & \multicolumn{2}{|c|}{ Facilidad en el acceso al servicio. } & Ordinal \\
\hline microcreditos obtenidos & \multicolumn{2}{|c|}{ Dificultades presentadas. } & Nominal \\
\hline & \multicolumn{2}{|c|}{ Acompañamiento a la obligación. } & Nominal \\
\hline & \multicolumn{2}{|l|}{ Precio del servicio. } & Ordinal \\
\hline & \multicolumn{2}{|c|}{ Deseo de continuar utilizando el servicio. } & Ordinal \\
\hline
\end{tabular}

Fuente: Elaboración de los autores. 
ANEXo 2.

Distribución de encuestas según número de establecimientos microempresariales en los subsectores manufactureros de la ciudad de Pasto por la clasificación CIIU para el año 2016 .

\begin{tabular}{|c|c|c|c|}
\hline $\begin{array}{l}\text { CIIU } \\
\text { Sección C }\end{array}$ & Industrias Manufactureras & $\begin{array}{l}\text { Participación } \\
\text { Porcentual }\end{array}$ & $\begin{array}{l}\text { Número } \\
\text { Encuestas }\end{array}$ \\
\hline 10 & Elaboración de productos alimenticios. & $23,76 \%$ & 75 \\
\hline 11 & Elaboración de bebidas. & $0,85 \%$ & 3 \\
\hline 12 & Elaboración de productos de tabaco. & $0,00 \%$ & - \\
\hline 13 & Fabricación de productos textiles. & $4,95 \%$ & 16 \\
\hline 14 & Confección de prendas de vestir. & $12,17 \%$ & 38 \\
\hline 15 & $\begin{array}{l}\text { Curtido y recurtido de cueros; fabricación de calzado; } \\
\text { fabricación de artículos de viaje, maletas, bolsos de mano y } \\
\text { artículos similares, y fabricación de artículos de talabartería } \\
\text { y guarnicionería; adobo y teñido de pieles. }\end{array}$ & $7,73 \%$ & 24 \\
\hline 16 & $\begin{array}{l}\text { Transformación de la madera y fabricación de productos } \\
\text { de madera y de corcho, excepto muebles; fabricación de } \\
\text { artículos de cestería y espartería. }\end{array}$ & $6,31 \%$ & 20 \\
\hline 17 & Fabricación de papel, cartón y productos de papel y cartón. & $0,40 \%$ & 1 \\
\hline 18 & $\begin{array}{l}\text { Actividades de impresión y de producción de copias a partir } \\
\text { de grabaciones originales. }\end{array}$ & $7,62 \%$ & 24 \\
\hline 19 & $\begin{array}{l}\text { Coquización, fabricación de productos de la refinación del } \\
\text { petróleo y actividad de mezcla de combustibles. }\end{array}$ & $0,11 \%$ & 1 \\
\hline 20 & Fabricación de sustancias y productos químicos. & $1,82 \%$ & 6 \\
\hline 21 & $\begin{array}{l}\text { Fabricación de productos farmacéuticos, sustancias químicas } \\
\text { medicinales y productos botánicos de uso farmacéutico. }\end{array}$ & $0,17 \%$ & 1 \\
\hline 22 & Fabricación de productos de caucho y de plástico. & $1,08 \%$ & 3 \\
\hline 23 & Fabricación de otros productos minerales no metálicos. & $1,71 \%$ & 5 \\
\hline 24 & Fabricación de productos metalúrgicos básicos. & $1,71 \%$ & 5 \\
\hline 25 & $\begin{array}{l}\text { Fabricación de productos elaborados de metal, excepto } \\
\text { maquinaria y equipo. }\end{array}$ & $6,88 \%$ & 22 \\
\hline 26 & Fabricación de productos informáticos, electrónicos y ópticos & $0,45 \%$ & 1 \\
\hline 27 & Fabricación de aparatos y equipo eléctrico. & $0,23 \%$ & 1 \\
\hline 28 & Fabricación de maquinaria y equipo n.c.p. & $1,08 \%$ & 3 \\
\hline 29 & $\begin{array}{l}\text { Fabricación de vehículos automotores, remolques y } \\
\text { semirremolques. }\end{array}$ & $2,10 \%$ & 7 \\
\hline 30 & Fabricación de otros tipos de equipo de transporte. & $0,00 \%$ & - \\
\hline 31 & Fabricación de muebles, colchones y somieres. & $6,48 \%$ & 20 \\
\hline 32 & Otras industrias manufactureras. & $5,40 \%$ & 17 \\
\hline \multirow[t]{2}{*}{33} & $\begin{array}{l}\text { Instalación, mantenimiento y reparación especializado de } \\
\text { maquinaria y equipo. }\end{array}$ & $6,99 \%$ & 22 \\
\hline & Total & $100 \%$ & 315 \\
\hline
\end{tabular}

Fuente: Cámara de Comercio (2016b). 
CARACTERÍSTICAS DEL MICROCRÉDITO EN LA INDUSTRIA MANUFACTURERA DE LA CIUDAD DE PASTO, AÑO 2016

Anexo 3.

Estadístico de asociación Chi-cuadrado con respecto a la satisfacción del servicio.

\begin{tabular}{llll}
\hline \multicolumn{2}{c}{ Decisión de continuar con el microcrédito vs: } & P-valor & $\begin{array}{c}\text { Nivel de confianza } \\
\text { estadística }\end{array}$ \\
\hline $\begin{array}{l}\text { El crédito recibido fue: Suficiente/ } \\
\text { Insuficiente }\end{array}$ & Pearson chi2(1)=3,37 & 0.066 & $*$ \\
$\begin{array}{l}\text { La empresa está satisfecha con el } \\
\text { servicio recibido }\end{array}$ & Pearson chi2(3) $=12,35$ & 0.006 & $* * *$ \\
El costo de servicio es & Pearson chi2(2) $=13,62$ & 0.001 & $* * *$ \\
\hline
\end{tabular}

Fuente: Cálculo de autores. 